\title{
Effects of 4 Weeks Home Based Single Leg Stance Exercise Programme in Senior Citizens Living in Rural and Urban Areas
}

\author{
Prachi Shardul $^{1}$, Deepali Hande ${ }^{2}$ \\ ${ }^{1}$ BPT, Dr APJ Abdul Kalam College of Physiotherapy, Pravara Institute of Medical Sciences, Loni (Bk), \\ 413736, Ahmednagar, Maharashtra, India. \\ ${ }^{2}$ Professor and HOD of Department of Community Physiotherapy, Dr. APJ Abdul Kalam College of \\ Physiotherapy, Pravara Institute of Medical Sciences, Loni (Bk), 413736, Ahmednagar, Maharashtra, India. \\ Corresponding Author: Prachi Shardul
}

\begin{abstract}
Background: Balance impairment is a common problem in senior citizens aged from 60 years and above to perform independently all the functional activities. Static balance exercise is performed as an exercise intervention which helps to strengthen the lower extremities, increase balance confidence and performance in senior citizens.

Purpose: To evaluate the effectiveness of 4 weeks home based single leg stance exercise programme in senior citizens living in rural and urban areas.

Methodology: After fulfilling inclusion and exclusion criteria, a written consent form was taken from all 30 senior citizens who were selected through simple random sampling. Activities Specific Balance Confidence (ABC) Scale and Timed Up and Go (TUG) Test was taken pre-intervention and postintervention. Out of which, 15 rural participants who visited the physiotherapy setting were given intervention through personal appointments and other 15 urban participants were given intervention through tele-rehabilitation. The intervention period consisted of 4 weeks, twice a day and 3 times a week.

Results: There was a significant difference in the ABC and TUG values in paired t-test considering pre-intervention and post-intervention results among rural and urban population. But there was no significant difference in $\mathrm{ABC}$ and TUG values in unpaired t-test considering post-intervention results between rural and urban population.
\end{abstract}

Conclusion: The effect of 4 weeks home based single leg stance exercise programme was effective in both the groups of population irrespective of living in rural or urban areas.

Keywords: Activities Specific Balance Confidence (ABC) Scale, Timed Up and Go (TUG) Test, Balance exercise - Single leg stance exercise.

\section{INTRODUCTION}

Ageing is outlined as a continuous method that starts at conception and continues till death. It is known as senescence characterized by progressive changes in tissues or organs of the body. The common features associated with ageing include loss of skin elasticity, the decline in immune competence, development of atherosclerosis, and cataract formation. There are two types of causes of ageing both intrinsic and extrinsic which interact with each other ${ }^{[1]}$. Ageing is stated as a complex process of adaptation to physical, social, and psychological changes across the lifespan ${ }^{[3]}$. The physiological changes in ageing are changes in the nervous system and musculoskeletal changes which lead to higher incidences of falls in senior citizens and reduced quality 
of life. Alzheimer's disease, Parkinson's disease, and Stroke are very commonly found where there is a nerve cell death and tissue loss throughout the brain affecting nearly all the function. The cortex starts to shrink with reduced blood flow in the brain leading to loss of memory, reduced learning, and intelligence. Vision is also affected by the decline in accommodation, glare tolerance, adaptations, and color discrimination affecting reading, balancing, and driving. There is also found a decline in touch sensation due to skin changes and reduced blood circulation to the brain and spinal cord is observed. The decline in sense of touch including vibration, pain, and temperature which affects simple handgrip, strength, and balance. Changes in the musculoskeletal system also can be seen due to a decline in muscle mass and reduction in muscle strength leading to a risk of fractures, frailty, reduced quality of life, and loss of independence to perform daily activities ${ }^{[2]}$. According to the World Health Organization (WHO) recommends that persons over the age of 65 years should practice aerobic physical activity for at least 150 minutes of moderate intensity or 15 minutes of high intensity per week. However, strengthening exercises should be performed at least twice a week, and balance was recommended at least three times a week. Balance exercise not only improves static balance but also dynamic balance in senior citizens. Static balance exercise improves the ability of movement and activity-specific balance. It also helps to improve postural sway ${ }^{[4]}$. There are various balance assessment scales like Timed Up and Go (TUG) Test, Tinetti Performance Oriented Mobility Assessment (POMA) Test, Berg Balance Scale (BBS), OneLegged Stance Test (OLST), Activities Specific Balance Confidence (ABC) Scale, Balance Evaluation Systems (BES ) Test,
Dynamic Gait Index (DGI), Figure of 8 Walk Test, Five Times Sit to Stand(5TSTS) Test, Fullerton Advanced Balance (FAB) Scale, 2 Minute Step Test, Toe Tap Test, Transfer Scales, and Physical Performance Tests. The two balance measures which were undertaken for this study to assess balance in senior citizens are The Timed Up and Go (TUG) Test and The Activities Specific Balance Confidence (ABC) Scale. In this study, $\mathrm{ABC}$ Scale is employed because it is a measure for senior citizens in the form of a questionnaire indicating extends on balance confidence while performing daily activities without losing balance or experiencing unsteadiness. TUG is used to assess functional mobility without the use of specialized equipment and training, as well as it can be performed in a small area. The time taken to stand up from a standard chair, walk 3 meters, turn, and walk back to the chair is noted. Time taken to complete the task by the senior citizen should be less than 20 seconds to be termed as functionally independent. If the person aged 60 years or above has been observed to take more duration to complete the task, he or she is not completely independent to perform various activities of daily living ${ }^{[4]}$. The aim of this study is to determine the effects of 4 weeks home-based single leg stance exercise programme in the senior citizens living in rural and urban areas. The objectives of this study are to assess balance confidence and balance performance in senior citizens living in rural and urban areas, before and after 4 weeks home-based single-leg stance exercise programme.

\section{MATERIALS AND METHODS STUDY DESIGN: Comparative Study}

SAMPLE SIZE: 30 participants.

STUDY DURATION: 6 months. 


\section{PROCEDURE:}

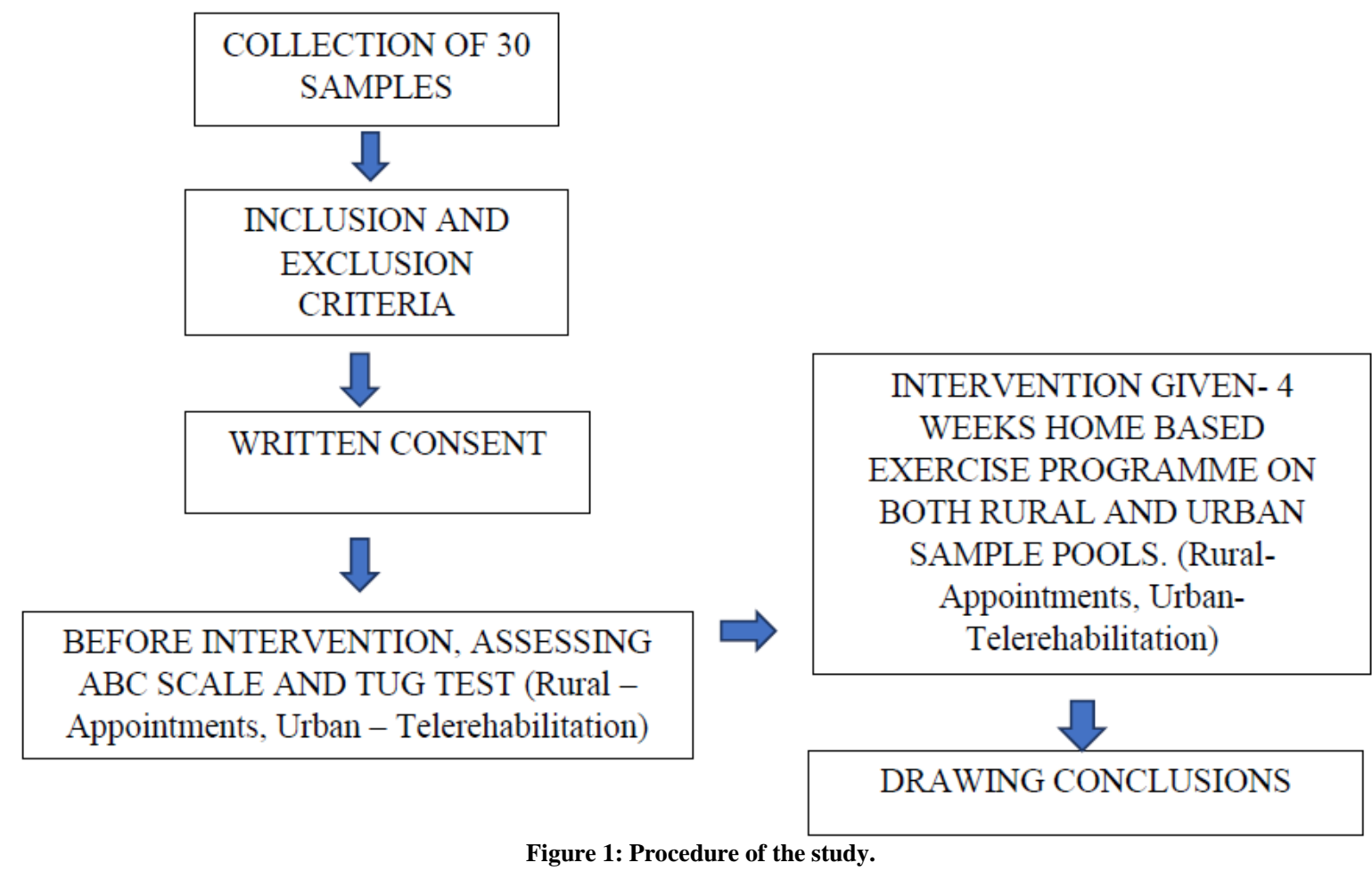

\section{INCLUSION CRITERIA:}

- Participants' age group should be minimum 60 years of age and above.

- Both participants males as well as females.

- Participants living in urban and rural areas.

- Participants should be medically stable.

- Participants with impairments leading to balance disorders.

- Participants with or without fear of fall.

- Participants willing to participate.

\section{EXCLUSION CRITERIA:}

- Participants below 60 years of age.

- Participants with severe neurological and orthopedic diseases.

- Participants with recent trauma or injury.

- Participants not willing to participate.

\section{TOOLS AND MATERIALS}

1. Metronome or clock with second hand was used for exercise and to assess TUG Test.
2. Chair was used for exercise and to assess TUG Test.

3. Tape was used to mark- 3-meter distance to assess TUG Test.

4. Written Consent Form.

5. Data Collection Sheet (Pen, Paper).

6. Evaluation Form.

7. Balance Exercises Static StandingSingle Leg Stance ${ }^{[12]}$.

8. Activities Specific Balance Confidence (ABC) Scale. ${ }^{[11]}$

9. Timed Up and Go (TUG) Test. ${ }^{[10]}$.

\section{Stastical Analysis:}

There were total 30 participants taken for this study, Two groups were formed consisting of participants living in rural and urban areas. Paired t-test was performed among participants living in the same area considering their pre-intervention and post-intervention results. The degree of freedom $(\mathrm{dF})$ for both rural and urban population for paired t-test was 14 . Unpaired t-test was performed between rural and urban participants by comparing their post-intervention results. The degree of freedom $(\mathrm{dF})$ for both rural and urban 
Prachi Shardul et.al. Effects of 4 weeks home based single leg stance exercise programme in senior citizens living in rural and urban areas.

population for unpaired t-test was 28 . The level of significance(a) was considered to be 0.05 in both group of participants living in rural and urban areas.
* Software used- Microsoft Excel 365; Version used- Office 2019*

\section{FINDINGS AND RESULTS}

\section{A) PRE AND POST INTERVENTION SCORES:}

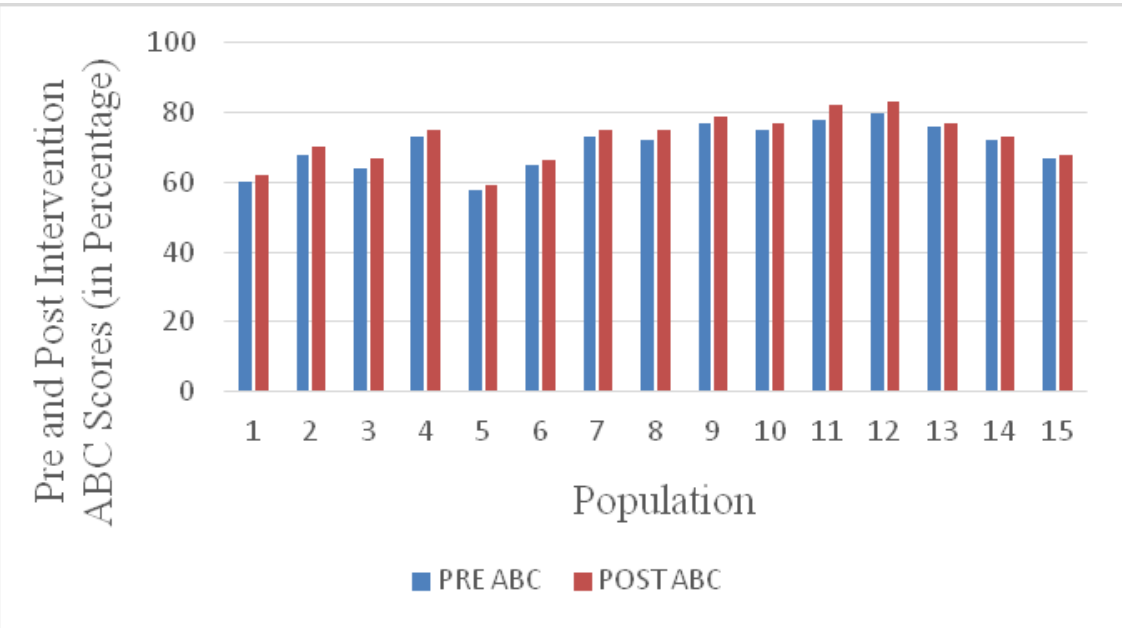

Figure 1: Pre and Post Intervention ABC Scale scores among Rural Population.

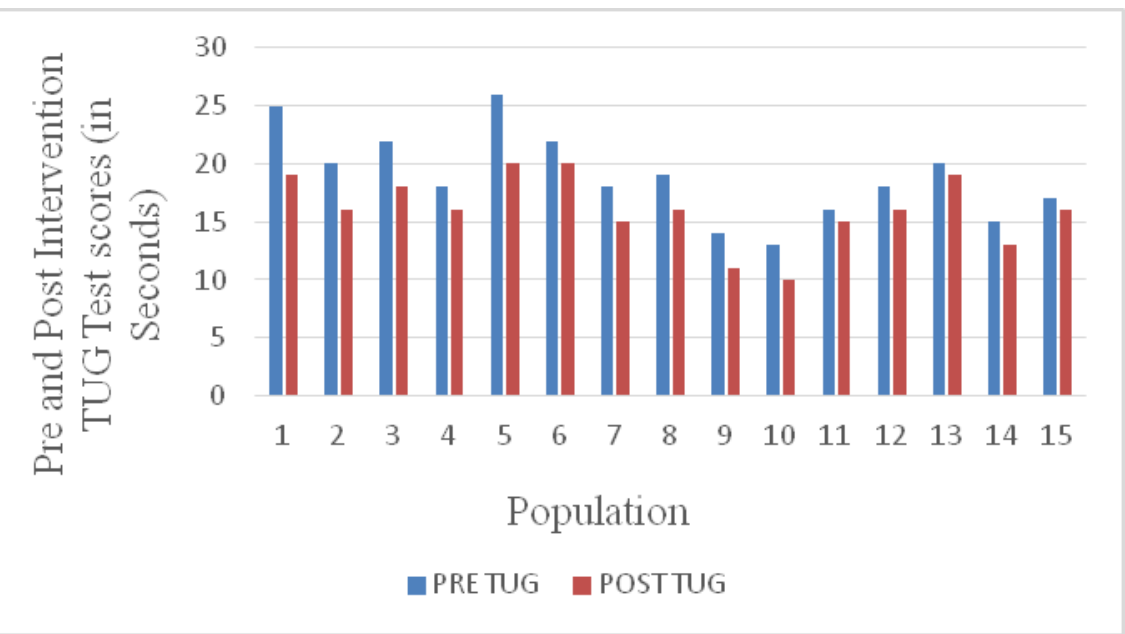

Figure 2 : Pre and Post Intervention TUG Test scores among Rural Population.

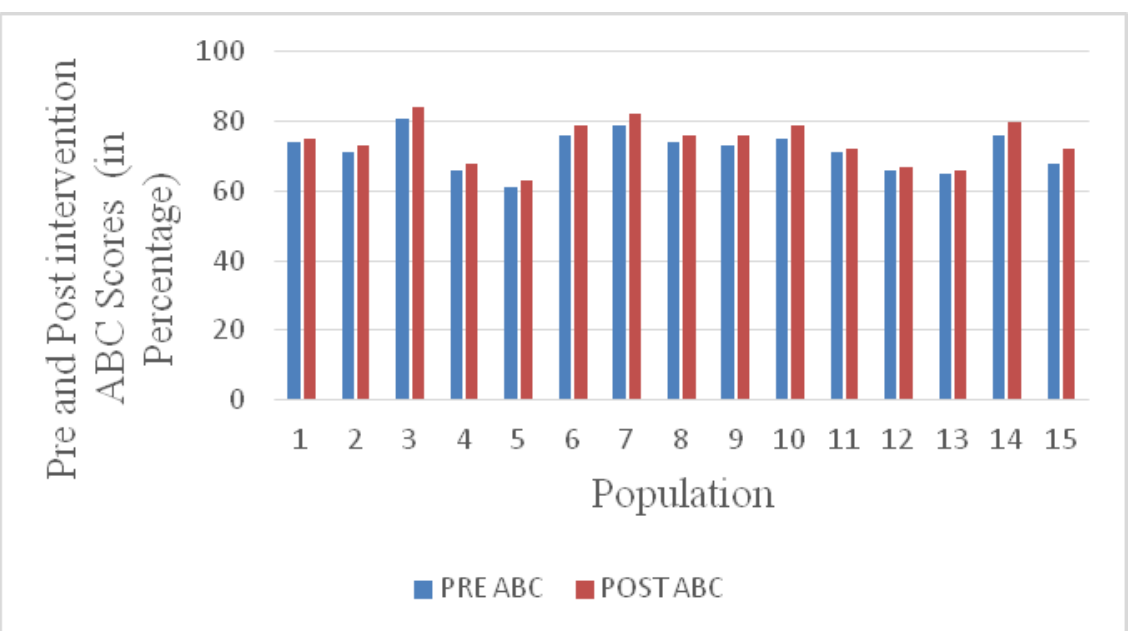

Figure 3: Pre and Post Intervention ABC Scale scores among Urban Population. 
Prachi Shardul et.al. Effects of 4 weeks home based single leg stance exercise programme in senior citizens living in rural and urban areas.

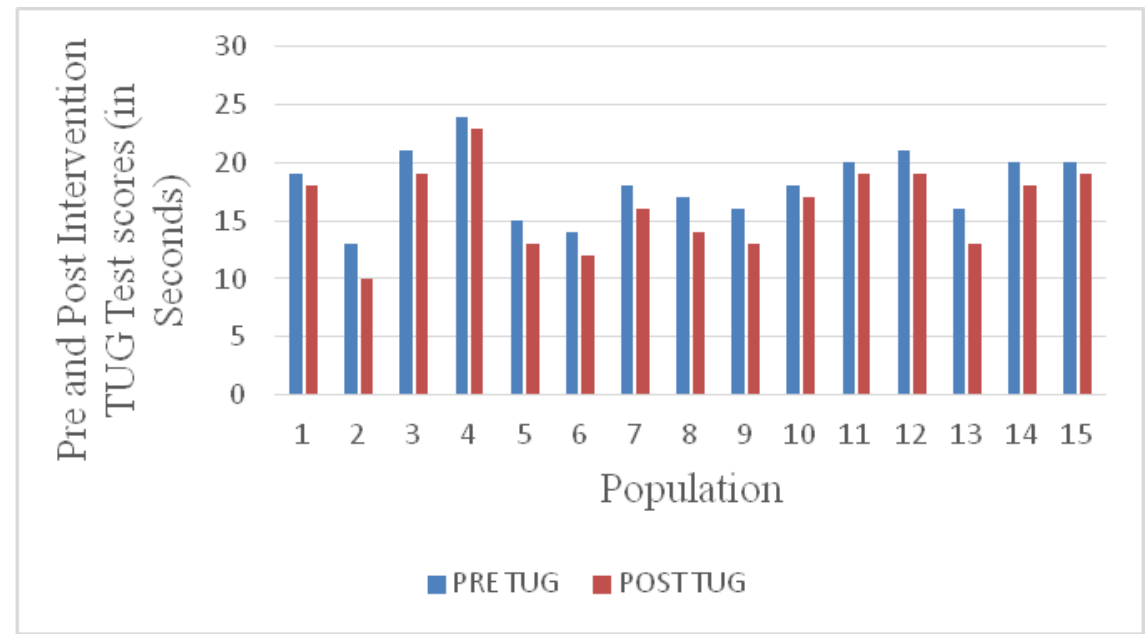

Figure 4: Pre and Post Intervention TUG Test scores among Urban Population.

Table 1: Pre and Post Intervention Scores

\begin{tabular}{|l|l|l|l|l|l|}
\hline POPULATION & BALANCE MEASURE & MEAN & STANDARD DEVIATION & PAIRED T-TEST & P VALUE \\
\hline RURAL & ABC SCALE & 2.0167 & 0.91 & 8.58 & 0.0005 \\
\hline RURAL & TUG TEST & 2.8 & 1.6 & 6.78 & 0.0005 \\
\hline URBAN & ABC SCALE & 2.4 & 1.12 & 8.3 & 0.0005 \\
\hline URBAN & TUG TEST & 1.93 & 0.8 & 9.344 & 0.0005 \\
\hline
\end{tabular}

Results conclude after paired t-test done within the same group of population, that there was a significant difference seen in pre-intervention and post-intervention values in rural and urban population due to an exercise intervention provided to senior citizens during this study.The critical value of paired t-test is 2.145 .

\section{B) POST INTERVENTION SCORES:}

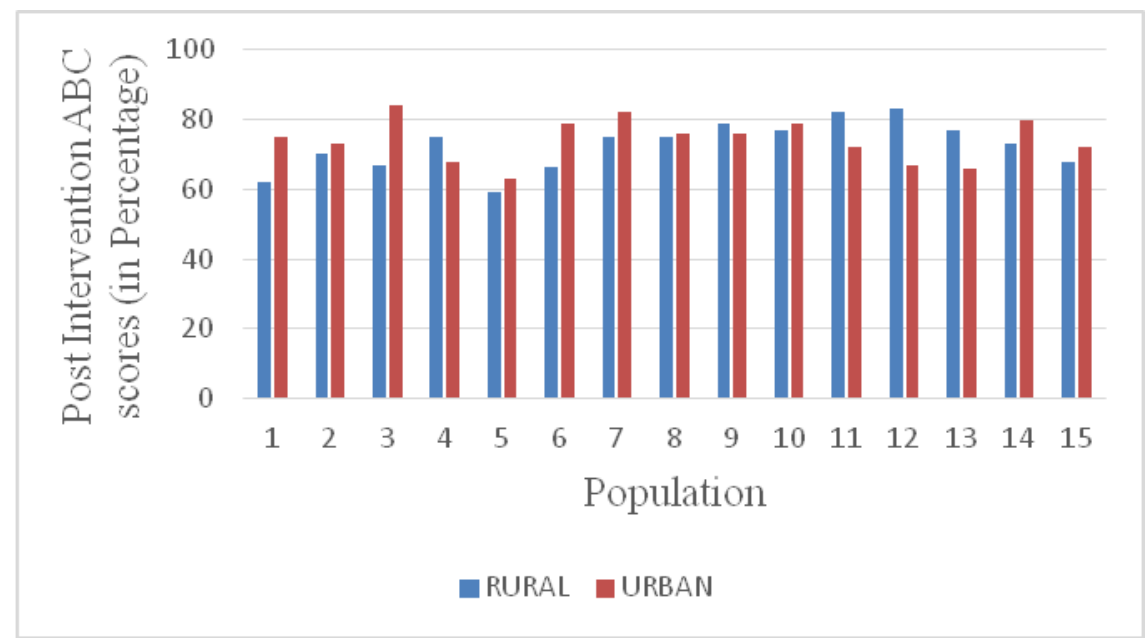

Figure 5: Post Intervention ABC Scale scores between Rural and Urban Population.

Table 2: Post Intervention Scores
\begin{tabular}{|l|l|l|l|l|l|}
\hline POPULATION & BALANCE MEASURE & MEAN & STANDARD DEVIATION & UNPAIRED T-TEST & P VALUE \\
\hline RURAL & ABC SCALE & 72.55 & 49.36 & 0.0142 & 0.50 \\
\hline URBAN & ABC SCALE & 74.13 & 38.41 & 0.0142 & 0.50 \\
\hline RURAL & TUG TEST & 16 & 3 & 0.1299 & 0.50 \\
\hline URBAN & TUG TEST & 16.2 & 3.55 & 0.1299 & 0.50 \\
\hline
\end{tabular}

Results conclude after Unpaired Ttest done between both the group of population to observe which group showed higher results. It was concluded that there was no significant difference in the post- intervention values in both rural and urban population due to an exercise intervention provided to senior citizens during this study. The critical value of unpaired t-test is 2.048 . 


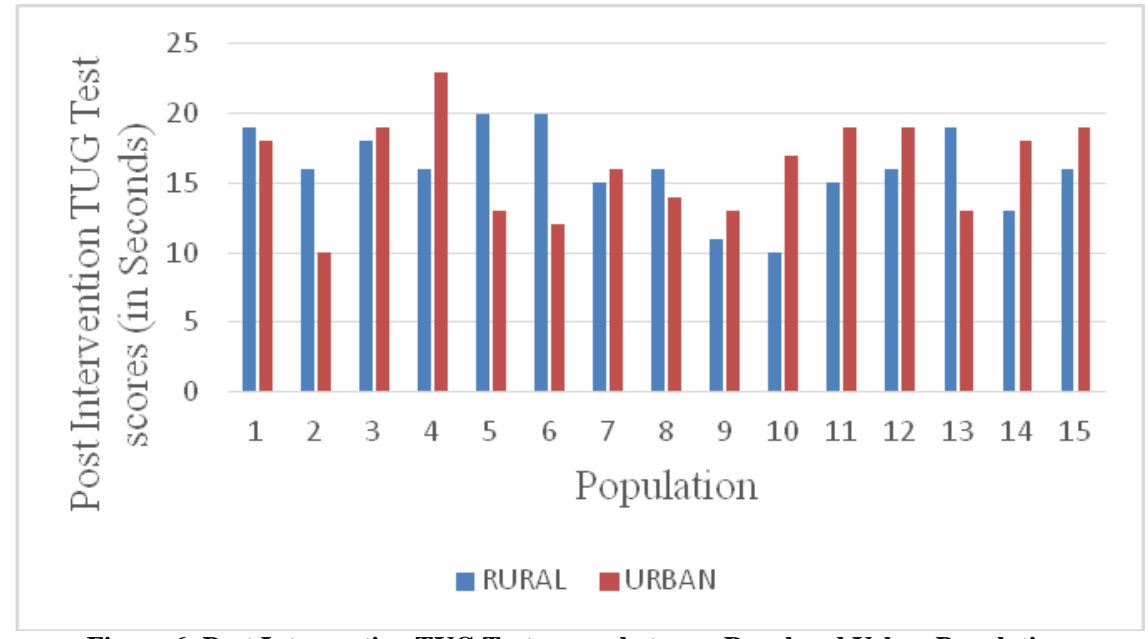

Figure 6: Post Intervention TUG Test scores between Rural and Urban Population.

\section{DISCUSSION}

The purpose of this study was to examine the effects of 4 weeks home-based single leg stance exercise programme in senior citizens living in rural and urban areas. The study was done to determine if balance can be learned with an exercise intervention given and to examine if any difference exists between rural and urban populations. The results of the study support the hypothesis that the 4 weeks of static balance training increases overall balance confidence and balance performance in senior citizens. These results support the findings of Stacey Schepens, Allon Goldberg, and Melissa Wallace $(2010)^{[8,9]}$. A similar study was done at the American Congress of Rehabilitation Medicine (2012) by Erja Portegijs, Johanna Edgren, Anu Salpokoski, et al, in a crosssectional study. The study was done to assess if balance confidence was associated with mobility and balance performance in older people with fall-related hip fractures. The result showed a correlation between the ABC Scale score and continuous mobility and balance performance. It showed a higher ABC scale score with lower TUG test scores which indicate better mobility and balance performance ${ }^{[7]}$. The TUG test measures the time taken by the participant to stand up from a chair, walking 3 meters, turn, and walk back to the chair. It was measured previously by the ordinal scale of 1 to 5 based on an observer's perception of the participant's risk of falling during the test. Podsiadlo and Richardson modified the original test by timing the tasks and proposed a short test for basic mobility skills for senior citizens. The intratester and intertester reliability (ICC) have been reported as high in senior citizens from 0.92 to 0.99 . Reliability in senior citizens has been found to be moderate (0.56). Validity has been observed by forming a relationship between TUG scores with gait speed (Pearson $r=0.75$ ), postural sway (Pearson $r$ $=-0.48)$, step length (Pearson $r=-0.79)$ and step frequency (Pearson $r=-0.59)^{[8,13]}$. The sensitivity and specificity have been reported to be $87 \%{ }^{[5]}$. The ABC Scale is a 16-item questionnaire to assess the level of confidence without losing balance or becoming unsteady. Each item score ranges from $0 \%$ (no confidence) to $100 \%$ (full confidence). Activity Specific Balance Confidence Scale (ABC Scale) is a selfreport questionnaire in which participants rate their balance confidence. It was first founded by Powell LE and Myers AM. An average score of 16 items was used. The ABC-Scale exhibits sublime results on internal consistency (Cronbach's $\alpha=0.916$ ) and substantial test-retest reliability (ICC $=0.86, \quad 95 \% \quad$ CI: 0.74-0.93), with standard error and minimal detectable change values of 8.64 and 16.94 respectively. According to various studies, the ABC Scale has been determined to be the best instrument available with valid 
measures of validity and reliability among senior citizens ${ }^{[4]}$. In this study, the use of both the scales, the ABC Scale for balance confidence and the TUG Test for balance performance showed significant results to conclude the result of the study.

\section{Limitations:}

- Participants lived away from the rehabilitation centre to educate themselves about the exercise intervention and to improve their balance confidence and balance performance.

- Participants had difficulty to independently get themselves assessed in a rehabilitation centre due to balance disorders.

- Lack of awareness about Physiotherapy and Rehabilitation Centres to improve their present balance disorders.

- Difficulty to fetch time for exercise intervention due to personal, social, environmental, and psychological problems.

\section{New Hypothesis/ Recommendation:}

- The future studies can perform other balance exercise intervention along with different measures to assess balance confidence and balance performance in senior citizens to study the effects of exercise intervention after a period.

\section{CONCLUSION}

The study concluded that the effect of 4 weeks home based single leg stance exercise programme was effective in both the groups of population of senior citizens irrespective of living in rural or urban areas. Therefore, static balance exercise like single leg stance exercise is an effective intervention to improve balance confidence and balance performance in senior citizens.

Conflict of Interest: The author declares that there were no conflicts of interest concerning the content of this present study.
Source of Funding: No funding was required.

Acknowledgement: None

\section{Ethical Approval: Approved}

\section{REFERENCES}

1. Nicolas R Balcombe, Alan Sinclair. Best Practice and Clinical Gastroenterology. 2001; 15(6):835-849.

2. Shilpa Amarya, Kalyani Singh and Manisha Sabharwal. Gerontology- Ageing Process and Physiological Changes; Grazia D' Onofrio, Antonio Greco and Daniele Sancarlo, Intech Open, DOI:10.5772/intechopen.76249; July $4^{\text {th }}$ 2018.3-24. Available from: https://www.intechopen.com/books/gerontol ogy/ageing-process-and-physiologicalchanges.

3. Nancye Peel, Helen Bartlett, Roderick McClure. Healthy ageing: how is it defined and measured? Australasian Journal on Ageing. September 2004;23(3):115-119.

4. Alharilla Montilla-Ibáñez, Antonio Martínez-Amat, Rafael Lomas-Vega et al. The Activities-specific Balance Confidence scale: reliability and validity in Spanish patients with vestibular disorders. Disability and Rehabilitation. 25 ${ }^{\text {th }}$ March 2016;39(7): 1-7.

5. Teresa M Steffen, Timothy A Hacker, Louise Mollinger. Age and Gender Related Test Performance in Community Dwelling Elderly People: Six Minute Walk Test, Berg Balance Scale, Timed Up and Go Test and Gait Speeds. Physical Therapy. February 2002;82(2):128-137.

6. M. Candice Ross, Alice Bohannon, Debra C Davis et al. The Effects of Short-Term Exercise Program on Movement, Pain, and Mood in the Elderly. Journal of Holistic Nursing. June 1999;17(2);139-147.

7. Erja Portegijs, Johanna Edgren, Anu Salpokoski et al. Balance Confidence was associated with Mobility and Balance Performance in Older People with FallRelated Hip Fracture: A cross sectional study. Arch Phys Med Rehabil. December (2012); 93(12):2340-2346.

8. Allon Goldberg, Stacey Schepens, Melissa Wallace et al. Concurrent Validity and Reliability of the Maximum Step Length 
Prachi Shardul et.al. Effects of 4 weeks home based single leg stance exercise programme in senior citizens living in rural and urban areas.

Test in Older Adults; J Geraitr Phys Ther. 2010;33(3):122-127.

9. Roger J Davis. The Effects of a Four Week Single Leg Balance Training Program on Balance Error Scoring System scores of the Trained and Untrained Leg [Internet]. Utah University: All Graduate Theses and Dissertations. 468;2009. Available from https://digitalcommons.usu.edu/etd/468.

10. Timed Up and Go Test (TUG Assessment) [Internet]. Centre for Disease Control and Prevention: Stopping Elderly Accidents, Deaths \& Injuries (STEADI);2017. Available from https://www.cdc.gov/steadi/pdf/TUG_testprint.pdf.

11. Powell, LE \& Myers AM. The Activities Specific Balance Confidence (ABC) Scale [Internet]. J Gerontol Med Sci ;1995; 50(1):M28-34. Available from https://cdn.ymaws.com/www.nypta.org/reso urce/resmgr/long_island/2017_April_23_Mi
ni_Conference/Correia_Balance_Outcome_ Meas.pdf.

12. Balance Exercise - Static Standing Single leg stance exercise [Internet]. Health System - University of Michigan. 2016.Available from

http://www.med.umich.edu/1libr/PMR/Bala nceExercises/StaticStanding_SingleLeg.pdf.

13. Steffen T, Hacker T, Mollinger L. Age- and gender-related test performance in community-dwelling elderly people: sixminute walk test, berg balance scale, timed up go test, and gait speeds. Phys Ther. 2002;82(2):128-137.

How to cite this article: Shardul P, Hande D. Effects of 4 weeks home based single leg stance exercise programme in senior citizens living in rural and urban areas. Int J Health Sci Res. 2021; 11(6): 301-308. DOI: https://doi.org/10. 52403/ijhsr.20210644 